Josefina Safar*

\title{
Translanguaging in Yucatec Maya signing communities
}

\author{
https://doi.org/10.1515/applirev-2017-0082
}

\begin{abstract}
This article looks at translanguaging practices in four Yucatec Maya communities with a high incidence of deafness in the peninsula of Yucatán, Mexico. Deaf and hearing community members draw from a broad spectrum of semiotic resources to interact with each other and with people from other villages in the region: they sign with different degrees of fluency, speak Yucatec Maya and/or Spanish, gesture, draw, point and incorporate objects in their physical surroundings. Human beings have a general tendency to communicate between and beyond different languages and modalities and to creatively adapt their semiotic repertoires to each other to negotiate meaning. On top of that, I show that sociolinguistic and cultural features of Yucatec Maya communities scaffold translanguaging practices. The rich inventory of conventional co-speech gestures of Yucatec Maya speakers, positive attitudes towards deafness and signed language and a critical amount of shared cultural knowledge facilitate communication between deaf and hearing and contribute to the emergence of similar sign languages in historically unrelated communities. The investigation of Yucatec Maya signing communities through a translanguaging lens allows us to critically deconstruct existing classifications of sign languages and varieties. Yucatec Maya Sign Languages are portrayed as a multi-layered network of different villages, families, generations and overlapping deaf and hearing spaces, where translanguaging takes place.
\end{abstract}

Keywords: translanguaging, shared sign languages, Yucatec Maya Sign Language, multimodality, language attitudes

\section{Introduction}

In this article, I investigate translanguaging practices in Yucatec Maya villages in the peninsula of Yucatán, Mexico. Due to a high incidence of deafness ${ }^{1}$ in small,

$12,4 \%$ in Chicán (Escobedo Delgado 2012), 1,4 \% in Cepeda Peraza, 6\% in Trascorral, no exact figure available for Nohkop.

*Corresponding author: Josefina Safar, Linguistics, Stockholm University, Stockholm, Sweden, E-mail: josefina.safar@ling.su.se

Ә Open Access. (C) 2019 Safar, published by De Gruyter. (c) BY-NC-ND This work is licensed under the Creative Commons Attribution-NonCommercial-NoDerivatives 4.0 License. 
face-to-face communities, indigenous sign languages have emerged, which are used by deaf and hearing community members. This creates an intricate multilingual, multimodal landscape, where people communicate with a broad spectrum of semiotic resources: they sign with different degrees of fluency, speak Yucatec Maya and/or Spanish, gesture, draw on the ground, point to or manipulate objects in their environment. Incorporating different languages and modalities and adapting them to specific dynamics of the communicative constellation is a general human capacity - what makes the Yucatec Maya context special? I argue that sociolinguistic features of Yucatec Maya signing communities facilitate communication between deaf and hearing individuals and stimulate the emergence of "shared sign languages" (Nyst 2012). A high use of conventionalised, often emblematic co-speech gestures (Section 5.1), coupled with positive attitudes towards deafness and signed language (Section 5.2) and a high degree of shared cultural knowledge (Section 5.3) open up abundant possibilities for deaf and hearing people to conjoin their semiotic repertoires.

Translanguaging encompasses the “deployment of a speaker's full linguistic repertoire without regard for watchful adherence to the socially and politically defined boundaries of named (and usually national and state) languages" (Otheguy et al. 2015: 281). Kusters et al. (2017) argue that communicative inventories are not only multilingual but inherently multimodal, introducing the term "semiotic repertoire": A semiotic repertoire contains a range of meaning-making resources that humans have at their disposal, including spoken and signed languages, gesture, fingerspelling, pointing, writing, pictorial symbols and elements of their physical surroundings. Translanguaging "creates a social space (...) by bringing together different dimensions of their personal history, experience and environment, their attitude, belief and ideology, their cognitive and physical capacity" (Wei 2011: 1223). The more dimensions are shared between language users and the more their repertoires overlap, the more easily meaning can be negotiated.

This article is based on data from four communities, whose members assert that signers from different villages have never been in contact with each other in the past. ${ }^{2}$ Their sign languages emerged independently from each other but display a number of striking resemblances in lexicon and grammar. On top of similarities rooted in the visual-gestural modality (Meier et al. 2002), these can be explained by their similar sociocultural setting - most importantly the common gestural substrate and cultural affiliation. I regard Yucatec Maya Sign

2 All four communities are located in the state Yucatán but one to several hours drive from each other. In rural Yucatán, people travel little and contact between villages is scarce if people are not kin-related. 
Languages (YMSLs) as a multi-layered network of villages, families and deaf and hearing spaces (Kusters 2015), where translanguaging happens. The examination of YMSLs under a translanguaging paradigm comes to challenge sign language classifications like "home sign" or "village sign language", revealing that YMSLs are not homogenous entities but hybrid in nature, constantly oscillating between conventionalisation, variability and (re)negotiation (see Green (2014) on "local sign" in Nepal). To grasp the essence of YMSLs, we need to break down boundaries between grammars, lexicons and modalities, between the linguistic, the cultural and the social.

Translanguaging theory has transformative power, not only because it "liberates language" from rigid definitions (García and Wei 2014: 42), but it also liberates the linguist from the task of squeezing into fixed categories linguistic realities which are messy and unpredictable. The application of a translanguaging paradigm to interactions that link spoken and signed languages has only recently gained more attention. While most of this research focused on urban contexts, such as Kusters (2017) on deaf-hearing interactions on Mumbai's markets, or on national sign languages (e.g. Zeshan, this issue; Tapio 2014), few studies have used the concept of translanguaging to explore communication including signed and spoken languages in rural communities (but see Moriarty, this issue, on rural Cambodia). My analysis of YMSLs makes three main contributions. First, communication between deaf and hearing individuals is facilitated by their shared gestural and cultural repertoires. However, I also point out limits to semiotic repertoires and show that experience with sign language allows talking about more context-removed topics than gesture. Second, Yucatec Maya translanguaging practices can explain the emergence of lexically and grammatically similar sign languages in unrelated communities. Finally, a translanguaging framework frees us from sign language classifications based on sweeping sociolinguistic criteria that cannot satisfyingly explain the dynamics of YMSL interactions.

\section{Language(s) and communities of study}

\subsection{Sociolinguistic profile of the communities}

So far, four signing communities with multiple deaf members have been identified in rural Yucatán, which differ from each other in their overall population size and number and distribution of deaf people (see Table 1). 
Table 1: Overview about YMSL signing population.

\begin{tabular}{|c|c|c|c|c|}
\hline Name & Population & $\begin{array}{l}\text { Number of } \\
\text { deaf people }\end{array}$ & $\begin{array}{r}\text { Age of deaf people } \\
\text { (approximately) }\end{array}$ & $\begin{array}{l}\text { Family distribution } \\
\text { of deaf people }\end{array}$ \\
\hline Chicán & $\begin{array}{l}720 \text { (Escobedo } \\
\text { Delgado 2012) }\end{array}$ & 17 & $14-81$ & Multiple families \\
\hline Nohkop ${ }^{3}$ & No exact figure & 4 & $15-22$ & $\begin{array}{l}\text { Siblings of one } \\
\text { family }\end{array}$ \\
\hline Trascorral & $\sim 100$ & 6 & $7-25$ & $\begin{array}{l}\text { Siblings of one } \\
\text { family }\end{array}$ \\
\hline $\begin{array}{l}\text { Cepeda } \\
\text { Peraza }\end{array}$ & $\sim 700$ & 10 & $28-45$ & Multiple families \\
\hline
\end{tabular}

YMSLs are young languages with a maximal depth of three generations ${ }^{4}$ of deafness in Chicán and only one generation in Nohkop, Cepeda and Trascorral. They are unrelated to Mexican Sign Language (LSM) and originated independently from institutional settings out of the everyday necessity for deaf and hearing people to communicate with each other. Language contact with LSM has been minimal in the past (Escobedo Delgado 2012: 379-380) but is now increasing among some younger signers, who get in touch with the deaf community from the regional capital Mérida. Only recently, the team of the Yucatec Maya Sign Language Project (see Section 3) started to investigate the sign languages of Trascorral and Cepeda, but previous studies have been carried out in Chicán (e.g. Shuman 1980; Johnson 1991; Le Guen 2012) and Nohkop (Le Guen Under review).

\subsection{One language, many languages? YMSL(s) and sign language classifications}

First comparative analyses of YMSLs mirror observations of YMSL signers, who describe sign languages of distinct Yucatec Maya communities as "similar but different" (see Section 5.2). Given the high incidence of deafness in villages across the peninsula, we can assume that signing communities and other YMSLs have existed in the past. However, there is no solid proof from historical documents or people's memories to sustain Fox Tree's (2009) claim of a pre-Hispanic pan-Mayan

3 Nohkop is a pseudonym for a small neighbourhood in the outskirts of the town Chemax, chosen according to the family's wish to remain anonymous.

4 However, a purely age-based notion of "generations" can be insufficient (Kisch 2012) and social networks of shared signing communities are better explained in terms of "interactional groups” (Le Guen 2012: 214-217). 
sign language. In-depth interviews, including the eldest community members, have failed to provide evidence for any historical link between the communities of study. Throughout the article - drawing from analyses of language practices and attitudes - I will underpin my use of the label "Yucatec Maya Sign Languages" for sign languages that emerged independently from each other in the same geographic region from a common gestural (see Section 5.1) and cultural (see Section 5.3) background. Similarities in lexicon and grammar go along with substantial inter- and intra-community variation, which is said to be typical of young rural sign languages (Meir et al. 2012). The existence of "familylects" has been mentioned by Sandler et al. (2011) for Al-Sayyid Bedouin Sign Language or Hou (2016) for San Juan Quiahije Chatino Sign Language (SJQCSL). As the Yucatec Maya interact primarily with their extended families, signers who are not directly related and live on opposite sides of Chicán have little contact and exhibit differences in their lexicons (Safar et al., Forthcoming). Thus, it is questionable whether speaking of a homogenous "Chicán SL" (as in Escobedo Delgado [2012]; or Zeshan et al. 2013) is adequate or if it should rather be considered a constellation of different "family sign languages" with an important degree of shared conventions, as Hou (2016) proposes for SJQCSL.

Where should YMSLs be placed on a hypothetical continuum of "sign language types", ranking from "home sign systems" to fully conventional "Deaf community sign languages"? Other authors (Nyst 2012; Green 2014) have challenged the idea of a continuum because it leaves some sign languages - such as YMSLs - "trapped somewhere in the middle of a developmental cline" (Nyst 2012: 568). Home sign, a term which presupposes language-like properties but a too low level of conventionalisation to be called "language", traditionally refers to the communication of isolated deaf individuals who grow up in a hearing environment without sign language exposure (Goldin-Meadow 2003). YMSLs in Nohkop and Trascorral are only used within a single family and have not (yet) been subject to deaf-to-deaf intergenerational transmission, which could justify their classification as home sign. It would not be appropriate, however, to judge these signers to be communicatively isolated: They do - in the absence of a previously established sign language - receive a rich amount of conventional gestural input from their hearing environment and have, over the course of only one generation, developed complex signed languages with stable lexical and grammatical conventions. Nyst et al. (2012) criticise that most "home sign" literature is based on settings where signers are educated following an oralist approach (mostly in the US), neglecting rural environments with little access to formal education but an extensive use of conventional gestures, e.g. in West Africa - or Yucatán.

The labels "village sign language” (e.g. Zeshan 2011), "indigenous sign language” (e.g. Nonaka 2009) or "shared sign language” (Nyst 2012) usually 
imply transmission from adult language models (Nyst 2012: 560), dense contact within and across generations of a village (Green 2014: 80), a peculiar socioeconomic/demographic constellation (Nonaka 2009) and isolation from other sign languages. The "temporally oriented” (Green 2014: 78) term “emerging sign languages" (Meir et al. 2010) is vague and tells nothing about the community setting of the language "in progress".

While each of the abovementioned labels captures a fragment of YMSL's language ecology, none of them encompasses language practices that move beyond community borders and, at the same time, fluctuate between families and generations of one community. Parameters like linguistic complexity, intergenerational transmission or language contact cannot be clearly delimited for YMSL. No current term satisfyingly spans the high level of variability within YMSL communities as well as the substantial degree of overlap between unrelated communities. While other researchers have tried to solve this conundrum by introducing a variety of new terms for scenarios in the "grey area" of the continuum (Nyst 2012: 568) (e.g. “communal home sign” [Zeshan 2011], "rural home sign", "family sign language" [Nyst et al. 2012]), it is time to deconstruct the classifications themselves. The lens of translanguaging theory helps to shift our attention from abstract categories to actual language use. Yucatec Maya signing communities, where translanguaging is the norm rather than an exception, provide a touchstone to challenge existing sign language classifications.

\section{Fieldwork and data collection}

In this article, I discuss linguistic data from elicitation tasks (using photo and video stimuli), semi-spontaneous narratives and natural conversations in YMSL along with ethnographic data gathered through participant observation, informal and semi-structured interviews. My methodological approach is best described as an instance of "linguistic ethnography" (Snell et al. 2015), where analyses of language and its social environment are closely intertwined.

During three fieldwork periods of six weeks each in 2013 and 2015 and ten weeks in 2016/2017, I stayed with families in the villages, visited deaf and hearing people in their homes and accompanied them during their everyday activities. ${ }^{5}$ Taking part in their routines, sharing meals, exchanging gossip while preparing tortillas, going to the milpa (cornfield), attending family celebrations and village gatherings, I was able to observe interactions between deaf and hearing villagers

5 In this article, there will be a focus on data from Chicán, where I spent the longest amount of time. 
and witness encounters with visitors from outside. Gradually learning YMSL has been both an aim and a side effect of my fieldwork and I always use YMSL in everyday interactions with deaf people. I am a fluent speaker of Spanish and over time also acquired basic knowledge of spoken Yucatec Maya.

My own background as a multilingual, hearing, female European academic inevitably shapes my role in the community and influences my perception of the phenomena of study (see also Kusters 2012). In this respect, I benefit tremendously from my cooperation with other members of the Proyecto Lengua de Señas Maya Yucateca (PLSMY) (ymslproject.org), who are native speakers of Yucatec Maya and/or native signers of YMSL. Our team trained deaf and hearing community members from Chicán and Nohkop to assist with transcriptions in ELAN, translations into Yucatec Maya and Spanish, data elicitation and analysis.

With deaf consultants, I conducted data collection in YMSL as much as possible. For longer, more fine-grained interviews, for instance about language attitudes, hearing research assistants (who have deaf parents or are other close relatives of the interviewees) interpreted between YMSL and Spanish. Interviews and elicitation with hearing participants were either carried out in Spanish by myself, or in Yucatec Maya in collaboration with my PLSMY colleagues.

\section{Language practices in Yucatec Maya signing communities}

\subsection{Spoken language}

The languages spoken in the communities are Yucatec Maya and Spanish. Yucatec Maya is an officially recognised national language of Mexico and children acquire it as their L1, although in public domains - most crucially education - Spanish is the dominant language. Yucatec Maya is primarily used in face-to-face settings and lacks a written tradition. Language planning activities in Mexico have put forward efforts to establish a written (standard) form of Yucatec Maya but in effect, only few people can write Maya, the vast majority of the population - if literate - uses Spanish for written communication.

\subsection{Sign language}

In Chicán, Nohkop, Trascorral and Cepeda, sign language is present in all domains of everyday life. In Nohkop and Trascorral, YMSL is mainly used within 
one (extended) family, an environment with a high degree of intimacy and shared knowledge. In Chicán, deaf people are distributed among multiple families and generations and deaf and hearing "spaces” (Kusters 2015) overlap in manifold ways. Frequent deaf-only interactions occur mainly within two interactional groups (Le Guen 2012: 216), where only deaf people share the same household. A group of deaf men regularly meet for a chat on a street corner, which attests that "deaf spaces" do indeed exist (Kusters 2010) - but they conform to general patterns of socialising in the village. Deaf-deaf interactions largely coincide with kinship relations and affinities between members of (extended) families, as it is customary among Maya people. Deaf people from different families do not mingle and, in some cases, even avoid each other because of political, religious and/or personal differences. Women - deaf as well as hearing - generally interact much less outside their household than their male counterparts. Gatherings that assembled all deaf signers in Chicán were always initiated by external factors, such as government/NGO programs or foreign researchers (Le Guen 2012: 214).

Hearing people's signing proficiency varies depending on their exposure to YMSL. As socialisation primarily takes place within the extended family, the most skilful signers are the ones that are kin-related or share a family compound with deaf people. Language competence, however, does not only lie within an individual but is contingent on the interlocutor (Green 2014: 85). Hearing signers, e.g. CODAs, often report to communicate with ease with their deaf relatives but to have trouble understanding deaf people from other families because they "sign differently".

Hearing people always sign when addressing deaf people directly but do not always sign to each other in the presence of deaf, speaking Yucatec Maya instead. This imposes limitations to the claim that "everyone has equal access to social expression and understanding" - an observation that MacDougall (2012: 202) makes after having carried out ethnography in Chicán - and adds to the deconstruction of shared signing communities as "deaf utopias" (Kusters 2010).

Hearing visitors from surrounding communities, who come regularly e.g. to do trade, are often well accustomed to signing in YMSL. Otherwise, they rely on hearing relatives of deaf community members as "interpreters". However, these situations of linguistic mediation are rather spontaneous, short and informal, while planned interpreting over a longer period of time, as it is carried out by specifically assigned professional interpreters for urban/national sign languages, does not exist.

In the next section, I provide an example of a Yucatec Maya "translanguaging space", in which deaf and hearing people from two villages are "both going between different linguistic structures and systems and going beyond them" (Wei 2011: 1222). 


\subsection{Translanguaging in Yucatán: An example}

The conversation described below was recorded in 2016 in Cepeda Peraza. I visited the house of a deaf woman named Abigail together with two research assistants from Chicán: Geli Collí Collí, a deaf YMSL signer, and Merli Collí Hau, a hearing CODA. We were accompanied by a hearing man and his hearing son, with whom I live when I am in Chicán.

During the time of recording, I was mostly sitting in the kitchen next door, interviewing Abigail's deaf and hearing sisters. I witnessed a beautifully creative, multilingual and multimodal interaction that unfolded over the course of three hours, combining an ample variety of semiotic resources in flexible ways.

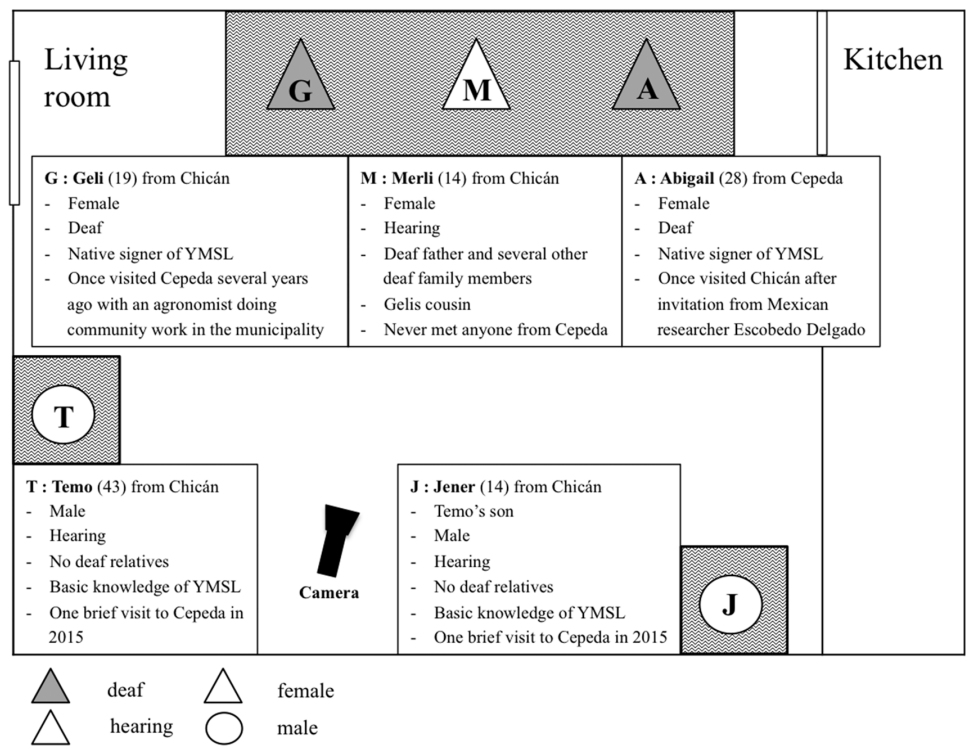

Figure 1: Seating arrangement and metadata.

The three women were sitting next to each other on the sofa (see Figure 1) and were instantly engaged in a lively conversation about their families, hobbies and routines. The two hearing men, seated opposite of them (see Figure 1), joined the conversation only for short episodes. Abigail, an outgoing person, repeatedly tried to involve the men in the discussion. She addressed them with conventional gestures (mostly isolated gestures with several repetitions) or enactments, often referring to culturally typical activities in a Yucatec Maya village (Section 5.3). They responded with gestures and pointings, sometimes speaking Maya simultaneously. In some occasions, Merli translated between YMSL and Maya. 
Abigail, Geli and Merli signed with increasing speed and did not seem to have difficulties understanding each other, even when they proceeded to topics like religion or marriage. In some domains, they encountered variation in their lexicons, e.g. for food, kinship or animals, which they usually resolved through descriptions. Instead of being an obstacle to understanding, they seemed to enjoy discovering these differences and over the course of the conversation, borrowed signs from each other, often accompanied by teasing remarks.

Abigail produces the sign BEANS used in Cepeda (depicting the characteristic manner how the plants spiral up a stick), followed by the interrogative sign QU-MARK ["What's your sign for 'beans"?"]. Merli and Geli give each other a questioning look (Figure 2a). Abigail provides a more detailed description of the vegetable's shape and growth (Figure 2b), followed by the
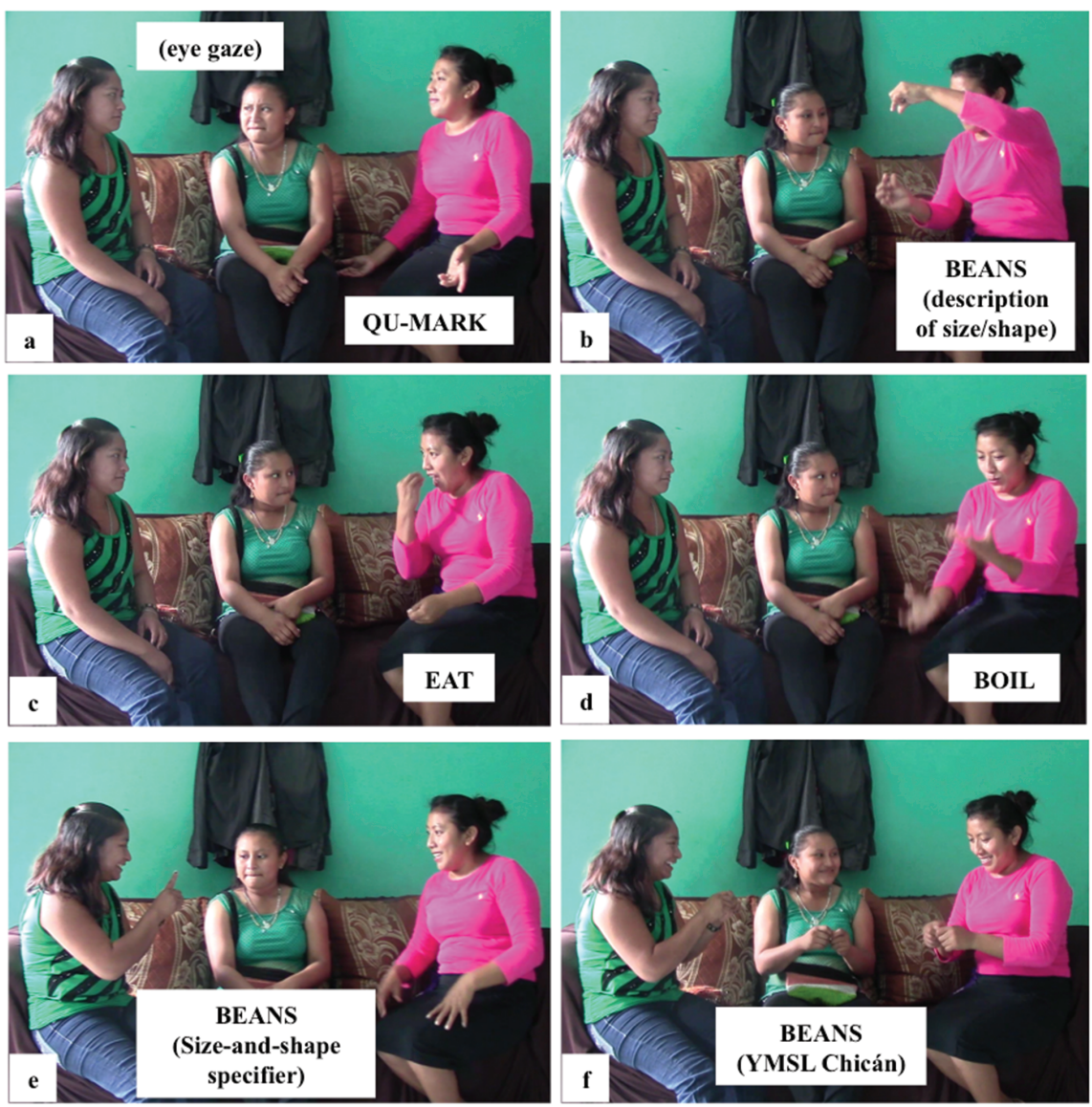

Figures 2: (a-f) Resolving lexical differences through descriptions. 
signs EAT and BOIL (Figures $2 c+d$ ). Geli understands and signs the Chicán variant for BEANS (derived from the action of taking beans out of their shell, followed by a size-and-shape specifier) (Figure 2e). Merli repeats it. Abigail laughs and they all simultaneously sign the Chicán variant (Figure 2f). ${ }^{6}$

The three of them made extensive use of conventional emblematic gestures used in Yucatán ('long time ago/ahead', 'a lot' [Figure 3a], 'finished'), countrywide ('yes' [Figure 3b], 'drink alcohol', 'money' [Figure 3c]) or internationally ('fine' [Figure 3d], "thumb-up") as well as signs based the enactment of typical cultural routines ('grind maize', 'wash clothes' [Figure 3e]) or other activities ('date', 'put on make-up' [Figure 3f]).

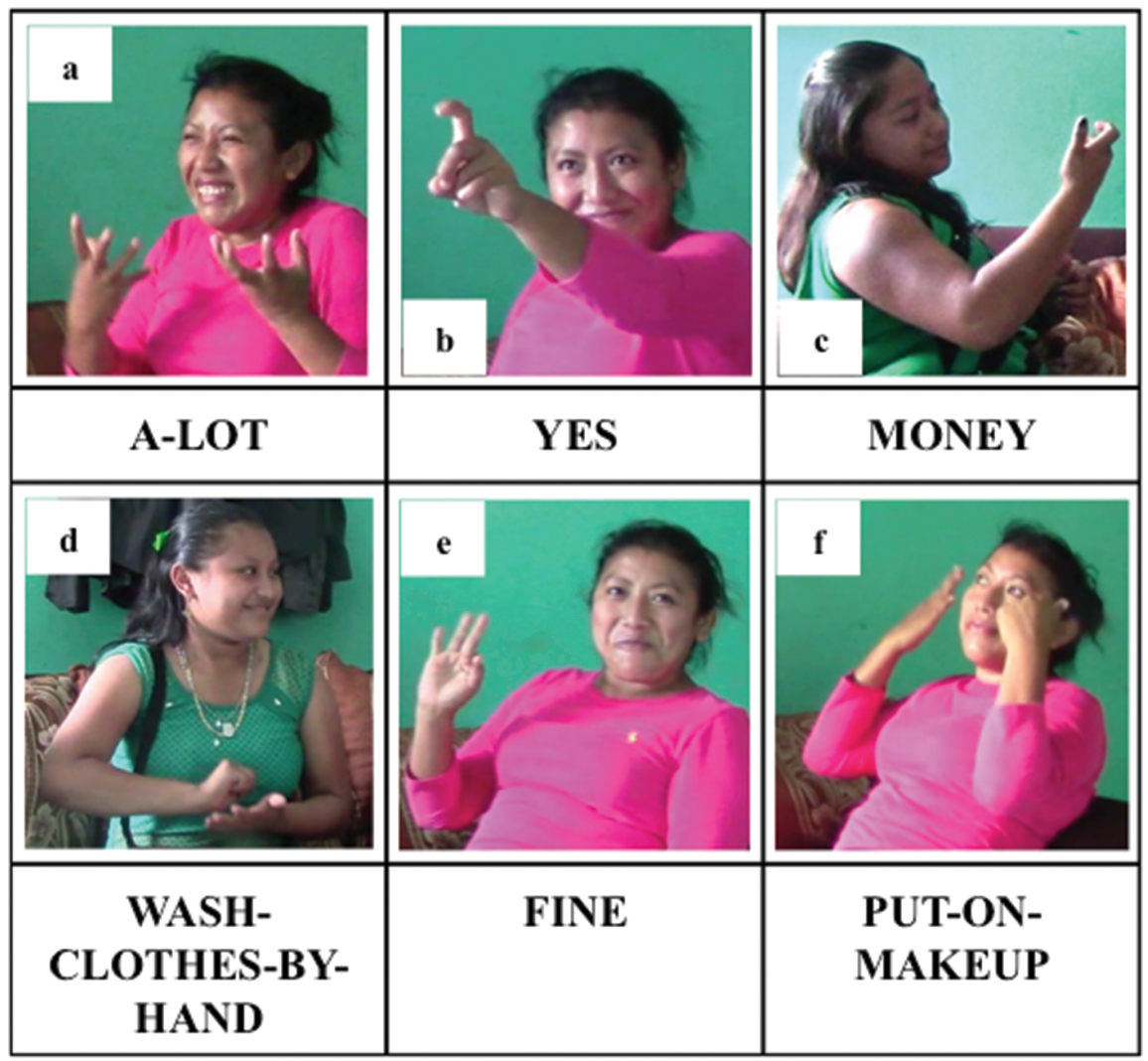

Figures 3: $(a-f)$ Gestures and enactments.

6 The style of narrating extracts from conversations and visualising them with screenshots from videos that I use in this article is adapted from Kusters (2017). 
In the number domain, misunderstandings arose. YMSL of Chicán has a separate lexeme for FIFTY (derived from the concept 'half') and uses an additive strategy to construct numbers up to 99 (Zeshan et al. 2013; Safar et al., Forthcoming). This strategy is unknown to Cepeda signers, which required Geli and Merli to fall back on alternative strategies.

On her phone, Geli shows Abigail a photo of her parents. Abigail points at the screen and asks FATHER (Figure 4a), followed by the interrogative sign HOW-MANY (Figure 4b)
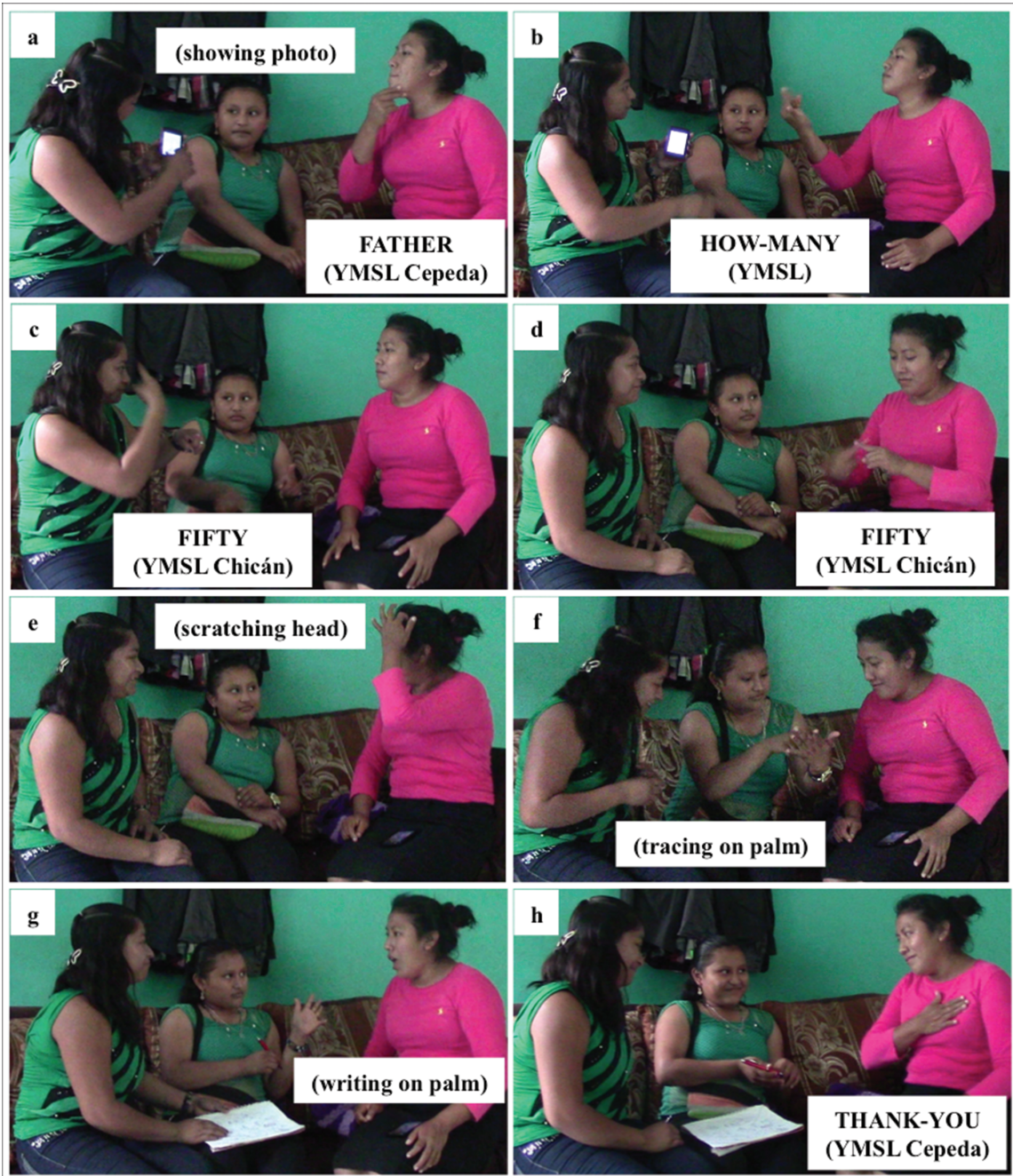

Figures 4: $(a-h)$ Non-understanding in the number domain. 
["How old is your father?"]. Geli responds with the number sequence FIFTY TEN FOUR ["64"] (Figure 4c). Abigail repeats FIFTY (Figure 4d), pauses and scratches her head, indicating her non-understanding (Figure 4e). Merli repeats FIFTY and traces 5-O with her finger on her palm (Figure 4f). Geli taps Abigail on her thigh and signs WRITE to ask for a pen. With a ballpoint, Merli writes ' 64 ' on her palm (Figure 4f). Abigail nods and asks MOTHER. Merli glances at Geli, who signs TWENTY TWENTY SEVEN ["47"]. Merli writes " 47 " on her hand and shows it to Abigail, who nods and signs THANK-YOU (Figure 4h).

Pictorial resources enriched their semiotic repertoires: Intrigued by exploring lexical similarities and differences, they drew plants and animals into a notebook and quizzed each other for the corresponding signs. Later, they took out their mobile phones, showed each other photos of relatives and acquaintances and told stories about them in YMSL.

The signers incorporated material resources in their immediate surroundings, by pointing to referents (e.g. fruit on a tree), touching objects (e.g. for colour descriptions) ${ }^{7}$ or handling objects (e.g. examining their self-made handbags to compare knitting techniques). The manipulation of objects and signing can also be simultaneously interlaced (Figure 5).

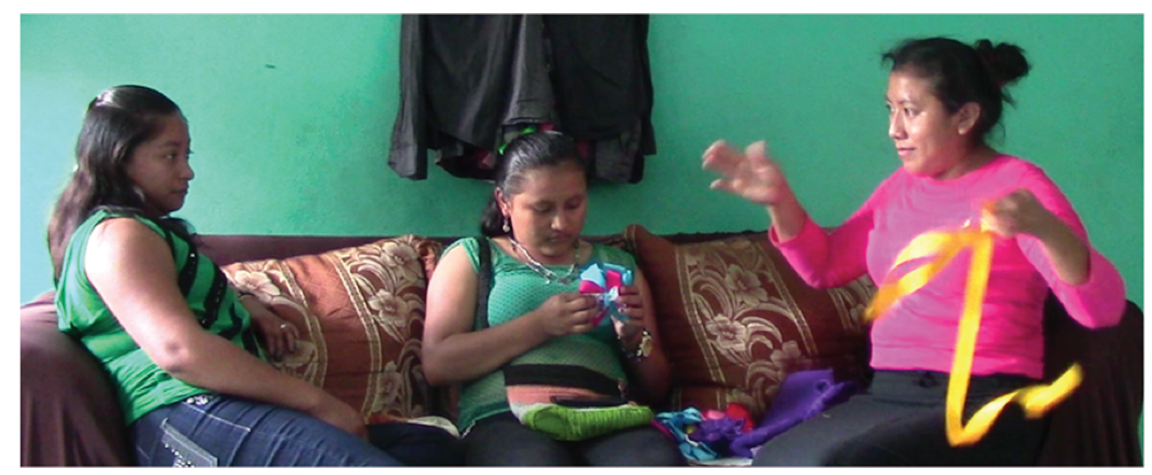

Figure 5: Signing while handling a ribbon.

Not all semiotic resources proved to be equally accessible for everybody: During few occasions Merli and Geli attempted to use the LSM manual alphabet for clarification. Fingerspelling did not turn out to be a successful approach because

7 This strategy became a fixed part of YMSL, which has only few lexicalised colour signs. All other colours are shown by pointing to or touching an object of the respective colour. 
Abigail is not very proficient in reading/writing, so they soon abandoned it in favour of other strategies.

Talking about food, Geli uses the Chicán variant for PINEAPPLE (Figure 6a). Abigail gives her a long look. Geli fingerspells the Spanish word P-I-Ñ-A (Figure 6b). Abigail looks at Merli, who starts drawing a pineapple into a notebook (Figure 6c). Abigail examines the illustration and gives a "thumb-up" gesture to confirm she has understood (Figure 6d).

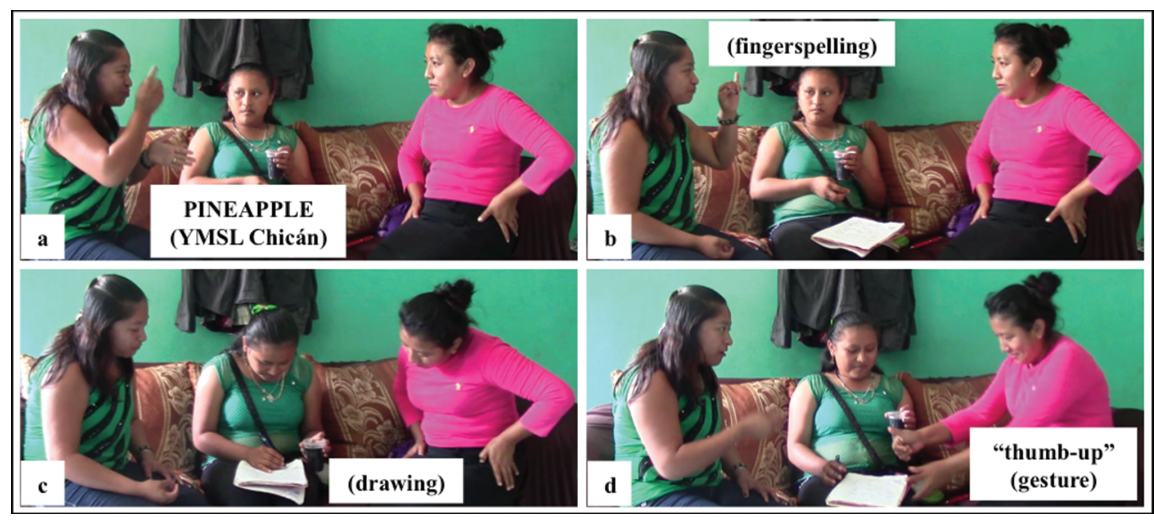

Figures 6: (a-d) Testing and discarding strategies: Fingerspelling.

Translanguaging is an inherently collaborative activity: interaction partners creatively interweave their semiotic repertoires, testing different strategies until mutual comprehension is established, as we can see in the examples "FIFTY" and "PINEAPPLE". "Chaining” (Humphries and MacDougall 1999) of different modalities and semiotic resources happens frequently, as shown in Figures $4 \mathrm{a}-\mathrm{h}$ and Figures $6 \mathrm{a}-\mathrm{d}$. In some aspects, this encounter is a typical instance of "cross-signing" (Zeshan, this issue) - and it is more than that. Signers who do not know each other and do not have access to a shared conventional sign language improvise and adjust their signing to each other in order to calibrate understanding. In addition to a universal human "translanguaging instinct" (García and Wei 2014: 32), Yucatec Maya cultural elements reinforced this process - but only to a certain extent. The uneven amount of overlap in their semiotic repertoires and asymmetries in access to communicative resources place the participants on variable distances from each other in a multi-layered "translanguaging space" (Wei 2011): the two hearing men are on the periphery of the interaction, while the three YMSL signers are in the centre and can communicate in more detail about a greater variety of topics. 


\section{Factors that facilitate translanguaging}

\subsection{Gesture among Yucatec Maya speakers}

One fundamental feature for translanguaging practices is the rich gestural repertoire of Yucatec Maya speakers, including different types of gestures, e.g. iconic, metaphoric, pointing or emblematic/quotable gestures (McNeill 1992; Kendon 2004). Crucially, what distinguishes Yucatec Mayan communication is not the sheer quantity of gestures in relation to speech but rather their quality: speakers are highly systematic in their gesture production, there is an important degree of consistency across individuals and their gestures are usually semantically rich, i.e. they complement speech in a meaningful way (Le Guen et al., Forthcoming; see also Kendon, 2004). In a comparative study, Petatillo Balam (2015) found that in Yucatec Mayan narratives, the gestural channel contributes more additional information to the story than in the ones of US English speakers (where gesture is mainly used for pragmatic and narrative organization). In many cases, looking at gestures in face-to-face interactions is indispensable for decoding the full linguistic message of a Yucatec Mayan utterance.

Because the Yucatec Maya already have a highly conventionalised gestural inventory, gestures can easily be taken up, become further lexicalised or grammaticalised into YMSL (Le Guen et al., Forthcoming). "Emblems" or "quotable gestures” (Kendon, 1992) with a stable form-meaning pairing, such as tak'in 'money' or bin 'go away', can be incorporated into YMSL without major semantic modification. In lexical comparisons, we notice that signs that are derived from emblems, depict typical everyday activities, e.g. P'O' ('WASH-CLOTHES-BY-HAND') or WAAJ ('TORTILLA') or highlight cultural characteristics, e.g. CH'UPAL ('GIRL') (which refers to the earrings Yucatec girls typically wear from early age) are usually identical or similar across communities. Lexical domains that are not gesturally encoded, e.g. colours (Le Guen, Under review), numbers (Safar et al., Forthcoming) or days of the week, result in distinct regional signs.

Shared gestural roots also give rise to similarities between YMSLs beyond the lexical level, e.g. strategies of time reference (Le Guen, 2012) or the use of the signing space (Le Guen and Safar, Unpublished Manuscript).

Being deeply anchored in peoples' semiotic repertoires, gesture partly explains the striking amount of consistency in the signing of individuals who have never been exposed to a shared conventionalised sign language (see also Nyst et al., 2012; for Mali or Green, 2014; for Nepal).

YMSL signers describe the transition from gesture to sign as gradual rather than categorical (see also Kendon, 2008): Recognising their obvious intersection, 
deaf people claim that gesture and sign are not the same and the accessibility of information through gesture remains limited. A deaf man from Chicán said he could understand "some things" from gestures in hearing people's conversations but "understands everything” in YMSL.

\subsection{Attitudes towards deafness and sign language}

As Kusters (2014: 142) points out, analyses of language practices and language attitudes need to go hand in hand. If and how hearing people engage in dialogue with deaf people heavily depends on whether they regard them as worthy conversation partners and consider the visual-spatial modality as an adequate means to convey information, on a par with the auditory one. I argue that in the Yucatec Maya context this is indeed the case and it is the sine qua non for translanguaging to unfold. This is in line with Green's (2014) view that successful communication is even more heavily dependent on the interactants' willingness to communicate than on a fully shared language.

Earlier accounts on YMSL already mentioned the absence of social segregation between hearing and deaf (Johnson 1991; MacDougall 2012; Escobedo Delgado 2012). Deafness is not perceived as something problematic among the Yucatec Maya (Le Guen 2012: 212) and this attitude forms a part of broader, cultural ideologies: Everybody is considered different and deafness is accepted as one of many imaginable manifestations of human diversity. In the communities of study, deaf residents are appreciated as competent and intelligent members of society and fulfil similar social roles as hearing people - they marry deaf or hearing partners, have children, are assigned responsibilities within the community etc. In Chicán and Cepeda, deaf people's marriage rate is somewhat lower than among the general population, but community members seem reluctant to provide an explanation for this phenomenon.

All people I interviewed agreed that deaf people need communication in the visual modality to unfold their potential. When I asked a hearing woman who assists the district doctor in the clinic if it was possible to express complex ideas in YMSL, she argued: "Of course! You can, for example, explain the difference between an influenza vaccine, an HIV test or a check-up for diabetes. If you explain it in sign language, they [the deaf; JS] understand everything!"»

A crucial disparity between deaf and hearing Yucatec Maya concerns their access to formal education and literacy. Deaf people usually receive only basic schooling (if any) in the local schools of the communities, relying on hearing

8 All quotes in this section are translated from Spanish by Josefina Safar. 
classmates as tutors. In Chicán, only the two youngest deaf kids attended secondary school and additionally received education in a centre for people with disabilities, with very little use of LSM. Traditionally, literacy did not play a major role in the communities - many hearing people of the older generation are not literate, either - but it is of rising importance today. This starts to create an imbalance of professional opportunities between hearing and deaf Yucatec Maya of the younger generation, similar to the "language ecological changes" that Nonaka (2012) describes in Ban Khor, Thailand.

In hearing people's language attitudes, two reoccurring statements formed a leitmotiv: "We are used to them!" and "They are used to us!" A hearing man in Chicán explains: "They are well adapted to our way of life. Here, we don't see it as a disability. That they don't hear is nothing that keeps us from communicating with them." Sign language use is perceived as a natural and indispensable result of deaf and hearing people living together: "That's how I grew up, since I can remember!" Familiarity and experiential knowledge with sign language (Kisch 2008) shape relationships between hearing and deaf. Individuals who moved to the communities later in life say that they were not able to understand YMSL in the beginning, but "with time we learnt to use our hands to show things".

People do not necessarily talk about signing as a language and foreground the pragmatic value rather than its linguistic properties: Signing is something that people $d o$, not so much an object of metalinguistic reflection. When asked "Which languages do you know?" hearing people would typically mention Spanish (as the "school language"), occasionally Yucatec Maya, but even the most proficient signers never named YMSL. What seems contradictory at first sight, makes perfect sense within a framework that focuses on language practice and views "language as an activity rather than a structure, as something we do rather than a system we draw on, as a material part of social and cultural life rather than an abstract entity" (Pennycook 2010: 2). Scholarly definitions of "language" might not necessarily coincide with local evaluations and moreover, direct questioning alone cannot fully reveal the intricacy of language users' attitudes.

Bridging my observations from language attitudes and practices, YMSL signers do frame their "languaging" as a coherent whole, which is not automatically transparent to outsiders, somehow distinct from sign languages in other communities, very different from the national sign language and more informative than co-speech gesture.

Those people who have met signers from other YMSL communities, describe their sign languages are "similar but different". Telling me about a visit from a group of deaf people from Cepeda (who were invited by Escobedo Delgado), a hearing man in Chicán comments: "I was impressed. Of course some things are 
similar - they are yucatecos like us. But even though they don't live far, their signs are not the same!" Regional and cultural affiliation to Yucatec Maya communities forms a link between linguistic structures that differ.

While YMSL signers from different communities see the delimitation of their sign languages as somehow fluid, their separation between YMSL and LSM is radical. Deaf and hearing people claim not to understand LSM (with exception of those few who have had exposure to LSM) when seeing it on television or meeting signers from Mexican cities, calling LSM "letters" or "signs from the book". Often reducing it to the manual alphabet, they evaluate LSM as inaccessible for non-literate people and, as a signer from Chicán puts it, "a complicated and time-consuming manner to communicate". YMSL, in contrast, is described as an efficient and natural way to express ideas "just as they come to your mind", perfectly shaped for the local lifestyle.

Within the past decades, various campaigns were initiated in Chicán by the Mexican government, NGOs and the church, aimed at improving deaf people's lives (MacDougall 2012; Safar 2015). In Chicán and Cepeda, Jehovah's witnesses attempted to teach deaf villagers LSM, but many of them rejected these interventions, explaining that they do not feel any necessity to learn another language. The distribution of hearing aids provoked a similar reaction. A resident of Chicán criticised that the government puts the wrong focus in wanting to make the deaf hear: "This is good in the eyes of the government. But this is not what we need!” MacDougall (2012) concludes that deaf people in Chicán do not incorporate negative assertions about their identity as needy and disabled. Signing is seen as an effortless, pleasant in-group activity and attempts to normalise deaf people according to external standards are depreciated.

\subsection{Shared context}

A third factor that reinforces translanguaging constellations in Yucatec Maya communities is the high degree of shared context. The communities of study - even though they are distributed across a relatively large geographical area - share common cultural traits and engage in similar everyday activities. Traditionally, men practice slash-and-burn agriculture, make daily trips to their milpa to cultivate crops, keep bees and go hunting. Women look after the house and domestic animals, grind maize at the mill, make fire, prepare tortillas. Additionally, men and women produce locally typical artefacts such as hammocks, baskets or embroidery. Children are socialised within the common family compound (solar). The annual cycle is structured by the harvest and a sequence of religious rituals and ceremonies - both traditional Yucatec Maya and Christian ones. 
Today, economic patterns are shifting and many people seek employment in nearby cities. Increased mobility, contact with the Mexican Deaf community, access to communication technology and social media transform the lives and social roles of (deaf) YMSL signers and extend their networks beyond community borders (Pacheco 2017). In contemporary Yucatec Maya communities, deaf and indigenous identities are complex and in flux (MacDougall 2012).

Notwithstanding, the communities of study exhibit a fair degree of social homogeneity (in terms of occupations, routines, biographies). Most people know each other and a lot of information does not need to be made explicit. This common "local experiential knowledge" (Kisch 2008: 300) characterises them as "shared signing communities". Meir et al. (2012) argue that due to the critical amount of shared knowledge, micro-community sign languages can tolerate considerable linguistic variation without imposing an obstacle on communication.

The shared repertoire of cultural heritage, rituals and beliefs across different Yucatec Maya communities makes it also - to a certain extent - easier to relate to each other's experiences even for strangers without a shared language. In the conversation described in Section 4.3, the two hearing men from Chicán were able to communicate about elements of Yucatec Maya culture with the deaf woman from Cepeda, relying on gestures and enactments. They discussed for instance about apiculture, the preparation of tamales (a typical Yucatec dish) or the religious pilgrimage of the antorchistas. Importantly, some of these culturespecific concepts are not transparent for outsiders unfamiliar with the local lifestyle. In the visual-gestural modality, an iconic relation between form and referent paves the way to similarities between historically unrelated sign languages, but the interpretation of iconicity lies "in the eye of the beholder" (Occhino et al. 2017). An iconic sign like TAMALES (which makes reference to the process of preparing the dish) becomes meaningful only if these practices are embedded in the interlocutor's experience. Iconicity lays a general cognitive foundation, shared context can scaffold much more concrete similarities between unrelated lexicons and grammars.

\section{Conclusion}

The analysis of Yucatec Maya translanguaging practices leads to three main conclusions. First, I demonstrated that - in addition to a general human "translanguaging instinct" (García and Wei 2014: 32) - cultural characteristics hold the key to access semiotic repertoires. The Yucatec Mayas' rich gestural inventory, positive attitudes towards deafness and sign language and shared knowledge 
within and across YMSL communities have repercussions on different levels: They are involved in sign language emergence when multiple deaf people are born into a community and facilitate comprehension with signers and nonsigners beyond community borders. I also showed that semiotic repertoires despite their permeability - can contain resources that are not equally accessible for everyone and experiential knowledge with YMSL is needed to negotiate more complex topics.

Secondly, my study makes a critical contribution to the debate 'YMSL varieties' vs. 'distinct sign languages' that has been spinning in circles in the literature. Based on the account of both language attitudes ("similar but different”) and language practices - where YMSL signers easily achieve mutual understanding across communities but also encounter gaps and languagespecific peculiarities - I propose a more comprehensive term using the plural "sign languages" in conjunction with the unifying label "Yucatec Maya".

Thirdly, classifications based on a scale from "fully conventional" sign languages to ad hoc, context-dependent home sign lose their validity through a translanguaging lens. Translanguaging not only softens languages and modalities but also permits transcending boundaries between communities, generations, deaf and hearing spaces. The examination of YMSLs ties in with Green's (2014) and Hou's (2016) fine-grained analyses of interactional practices and communicative ecologies in Nepal and Oaxaca (Mexico). Instead of placing YMSLs somewhere "half-way" on the continuum, my account of translanguaging in Yucatec Maya signing communities moved sign languages from the "grey area" (Nyst 2012: 568) into the centre of attention, allowing to capture their multifaceted communicative settings in a comprehensive way.

Acknowledgements: I wish to thank Annelies Kusters, Verena Krausneker, Johanna Mesch, Olivier Le Guen and two anonymous reviewers for their thorough feedback on earlier drafts of this paper. My gratitude goes to my research assistants Geli Collí Collí and Merli Collí Hau for their input and support and to members of the YMSL communities for translanguaging with me.

\section{References}

Delgado, Escobedo \& Cesar Ernesto. 2012. Chican Sign Language: A sociolinguistic sketch. In Ulrike Zeshan \& Connie De Vos (eds.), Sign Languages in Village Communities: Anthropological and Linguistic Insights, 377-380. Berlin: De Gruyter Mouton. Fox Tree, Erich. 2009. Meemul Tziij: An Indigenous Sign Language Complex of Mesoamerica. Sign Language Studies 9(3). 324-366. 
García, Ofelia \& Li Wei. 2014. Translanguaging: Language, Bilingualism and Education. Translanguaging: Language, Bilingualism and Education. London: Palgrave MacMillan. doi:10.1057/9781137385765.

Goldin-Meadow, Susan. 2003. The Resilience of Language: What Gesture Creation in Deaf Children Can Tell Us About How All Children Learn Language. New York: Psychology Press.

Green, Elizabeth Mara. 2014. The Nature of Signs: Nepal's Deaf Society, Local Sign, and the Production of Communicative Sociality. Berkeley: University of California, PhD dissertation.

Hou, Lynn Y-S. 2016. "Making hands": Family sign languages in the San Juan Quiahije community. Austin: University of Texas, PhD dissertation.

Humphries, Tom \& Francine MacDougall 1999. “Chaining” and other Links. Making connections between American Sign Language and English in two types of school settings. Visual Anthropology Review 15. 84-94.

Johnson, Robert E. 1991. Sign Language, Culture, and Community in a Traditional Yucatec Maya Village. Sign Language Studies 73. 461-474. doi:10.1353/sls.1991.0031.

Kendon, Adam. 1992. Some recent work from Italy on quotable gestures (emblems). Journal of Linguistic Anthropology 2(1). 92-108. doi:10.1525/jlin.1992.2.1.92.

Kendon, Adam. 2004. Gesture: Visible Action as Utterance. Cambridge: Cambridge University Press.

Kendon, Adam. 2008. Some reflections on the relationship between "gesture" and "sign." Gesture 8(3). 348-366. doi:10.1075/gest.8.3.05ken.

Kisch, Shifra. 2008. "Deaf discourse": the social construction of deafness in a Bedouin community. Medical anthropology 27(3). 283-313. doi:10.1080/01459740802222807.

Kisch, Shifra. 2012. Demarcating generations of signers in the dynamic sociolinguistic landscape of a shared sign language: The case of the Al-Sayyid Bedouin. In Ulrike Zeshan \& Connie de Vos (eds.), Sign Languages in Village Communities: Anthropological and Linguistic Insights, 87-125. Berlin: De Gruyter Mouton.

Kusters, Annelies. 2010. Deaf utopias? Reviewing the sociocultural literature on the world's “Martha's Vineyard situations" Journal of Deaf Studies and Deaf Education 15(1). 3-16. doi:10.1093/deafed/enp026.

Kusters, Annelies. 2012. Being a deaf white anthropologist in Adamorobe : Some ethical and methodological issues. In Ulrike Zeshan \& Connie De Vos (eds.), Sign Languages in Village Communities: Anthropological and Linguistic Insights, 27-52. Berlin: De Gruyter Mouton.

Kusters, Annelies. 2014. Language ideologies in the shared signing community of Adamorobe. Language in Society 43(2). 139-158. doi:10.1017/S0047404514000013.

Kusters, Annelies. 2015. Deaf space in Adamorobe: An Ethnographic study in a village in Ghana. Washington, DC: Gallaudet University Press.

Kusters, Annelies. 2017. Gesture-based customer interactions: deaf and hearing Mumbaikars' multimodal and metrolingual practices. International Journal of Multilingualism. 1-20. doi:10.1080/14790718.2017.1315811.

Kusters, Annelies, Massimiliano Spotti, Ruth Swanwick \& Elina Tapio. 2017. Beyond languages, beyond modalities: transforming the study of semiotic repertoires. International Journal of Multilingualism. 1-14. doi:10.1080/14790718.2017.1321651.

Le Guen, Olivier. 2012. An exploration in the domain of time: from Yucatec Maya time gestures to Yucatec Maya Sign Language time signs. In Ulrike Zeshan \& Connie De Vos (eds.), Sign languages in village communities: Anthropological and Linguistic Insights, 209-250.

Berlin: De Gruyter Mouton. 
Le Guen, Olivier. Under review. Esbozo de la situación sociolingüística de la(s) lengua(s) de señas maya yucateca(s). Mexico D.F.: CIESAS \& INALI.

Le Guen, Olivier, Rebeca Petatillo Balam \& Rita Kinil Canché. Yucatec Maya multimodal interaction as a proto Yucatec Maya Sign Language. Forthcoming in Olivier Le Guen, Josefina Safar \& Marie Coppola (eds.), Emerging Sign Languages of the Americas. Berlin: De Gruyter Mouton.

Le Guen, Olivier \& Josefina Safar. Unpublished Manuscript. Intergenerational evolution of the use of signing space in YMSL.

MacDougall, Jennifer Paige. 2012. Being Deaf in a Yucatec Maya Community: Communication and Identity Negotiation. Montreal: McGill University, PhD dissertation.

McNeill, David. 1992. Hand and Mind. What Gestures Reveal About Thought. Chicago: University of Chicago Press.

Meier, Richard, Kearsy Cormier \& David Quinto-Pozos. 2002. Modality and Structure in Signed and Spoken Languages. Cambridge: Cambridge University Press.

Meir, Irit, Assaf Israel, Wendy Sandler, Carol Padden \& Mark Aronoff. 2012. The influence of community on language structure. Evidence from two young sign languages. Linguistic Variation 12(2). 247-291.

Meir, Irit, Wendy Sandler, Carol Padden \& Mark Aronoff. 2010. Emerging Sign Languages. In Marc Marschark \& Patricia Elizabeth Spencer (eds.), Oxford Handbook of Deaf Studies, Language, and Education, 267-280. Oxford: Oxford University Press.

Nonaka, Angela. 2009. Estimating size, scope, and membership of the speech/sign communities of undocumented indigenous/village sign languages: The Ban Khor case study. Language and Communication 29. 210-229.

Nonaka, Angela. 2012. Language ecological change in Ban Khor, Thailand: An ethnographic case study of village sign language endangerment. In Ulrike Zeshan \& Connie De Vos (eds.), Sign Languages in Village Communities: Anthropological and Linguistic Insights, 277-312. Berlin: De Gruyter Mouton.

Nyst, Victoria. 2012. Shared sign languages. In Roland Pfau, Markus Steinbach \& Bencie Woll (eds.), Sign Language: An International Handbook, 552-574. Berlin: De Gruyter Mouton.

Nyst, Victoria, Kara Sylla \& Moustapha Magassouba. 2012. Deaf signers in Doentza, a rural area in Mali. In Ulrike Zeshan \& Connie De Vos (eds.), Sign Languages in Village Communities: Anthropological and Linguistic Insights, 251-276. Berlin: De Gruyter Mouton.

Occhino, Corrine, Benjamin Anible, Erin Wilkinson \& Jill Morford. 2017. Iconicity is in the eye of the beholder: How language experience affects perceived iconicity. Gesture 16(1). 100-126.

Otheguy, Ricardo, Ofelia García \& Wallis Reid. 2015. Clarifying translanguaging and deconstructing named languages: A perspective from linguistics. Applied Linguistics Review 6(3). 281-307. doi:10.1515/applirev-2015-0014.

Pacheco, Maribel. 2017. Nuevas estratégias de relaciones de sordos con el exterior en la actualidad: Trayectorias de comunicación de las y los sordos de Chicán, una comunidad maya en Yucatán. Mexico City: UNAM, MA thesis.

Pennycook, Alastair. 2010. Language as a Local Practice. New York: Routledge.

Petatillo Balam, Rebeca. 2015. Gestos espontáneos que acompañan el habla entre los hablantes de maya yucateco. José Maria Morelos: Universidad Intercultural Maya de Quintana Roo, BA thesis.

Safar, Josefina. 2015. Eine Analyse von Diskursen über Chicán Sign Language (Mexiko). Das Zeichen 101(1). 434-446. 
Safar, Josefina, Olivier Le Guen, Geli Collí Collí \& Merli Collí Hau. Forthcoming. Numeral variation in Yucatec Maya Sign Languages. In Sign Language Studies.

Sandler, Wendy, Mark Aronoff, Irit Meir \& Carol Padden. 2011. The gradual emergence of phonological form in a new language. Natural Language and Linguistic Theory 29(2). 503-543. doi:10.1007/s11049-011-9128-2.

Shuman, Malcolm K. 1980. The Sound of Silence in Nohya: A Preliminary Account of Sign Language Use by the Deaf in a Maya Community in Yucatan, Mexico. Language Sciences 2(1). 144-173.

Snell, Julia, Sara Shaw \& Fiona Copland. 2015. Linguistic Ethnography: Interdisciplinary Explorations. London: Palgrave MacMillan.

Tapio, Elina. 2014. The Marginalisation of Finely Tuned Semiotic Practices and Misunderstandings in Relation to (Signed) Languages and Deafness. Multimodal communication 3(2). 131-142.

Wei, Li. 2011. Moment Analysis and translanguaging space: Discursive construction of identities by multilingual Chinese youth in Britain. Journal of Pragmatics 43(5). 1222-1235. doi:10.1016/j.pragma.2010.07.035.

Zeshan, Ulrike. 2011. Village Sign Languages: A Commentary. In Gaurav Mathur \& Donna Jo Napoli (eds.), Deaf around the World: The Impact of Language, 221-230. Oxford: Oxford University Press.

Zeshan, Ulrike, Cesar Ernesto Escobedo Delgado, Hasan Dikyuva, Sibaji Panda \& Connie De Vos 2013. Cardinal numerals in rural sign languages: Approaching cross-modal typology. Linguistic Typology 17(3). 357-396. doi:10.1515/lingty-2013-0019. 